\title{
Subjective Health and Quality of Life of the Elderly in Korea
}

\author{
Mi-Ran Lee \\ Department of Social Welfare, Kosin University, Korea
}

Submission: July 25, 2017; Published: August 29, 2017

*Corresponding author: Mi-Ran Lee, Department of Social Welfare, Kosin University, 194 Wachi-Ro Yeongdo-Gu, Busan, Korea, Tel: +82-51990-2529; Fax:+82-51-990-2160; Email: dsmr0815@naver.com

\begin{abstract}
The useful actions on quality of high level life that allow human beings, who have lived in the era of global aging, to spend happy old age, are becoming very important tasks. Especially the health of the elderly is not only top priority of life but acts as a factor that controls various national, family and social policies and institutional systems. For this, the formal system and informal support system should be established in many ways since it adjusts the support of family resource on the elderly as well as influences to the quality of life of family in the old age. This study intends to discuss on the successful and happy life by improving the daily life health of the elderly, compensating the family support system on the elderly. The improvement of the quality of life of elderly is highly related to the positive finish and happiness of old age. Therefore, we should provide various supports of formal, non-formal support system of old age, excavate the alternative resource which can replace family support, and expand the multi-dimensional care system for the elderly living alone and the elderly in need by developing and strengthening the support system which can be supplemented.
\end{abstract}

Keywords: The Elderly; Quality of life; Happiness; Alternative resource; Care system

\section{Introduction}

Now the elderly accounts for the majority of society in Korea of which the speed of aging is the fastest among OECD members. In particular, the rapid increase of numbers of the elderly brought the increase of the elderly who need help, or unhealthy elderly, maintaining and improving the health of the elderly has been a social issue gradually. According to National Statistical Office, Korea is expected to reach an aged society since its elderly population exceeding $14 \%$ in 2018 and $21 \%$ in 2026 [1]. In order to enjoy high quality of life in the old age when elderly population increases, the interest on the health became more increased, we can say such a health condition of the old age is important as it is achieved when physical, psychological, and social factors balance each other.

The old age is the time to sort the life, accept the death ultimately, also the time to solve many problems in the view of physical, psychological and social [2]. In case of the elderly who is losing close persons due to death of spouse, retirement and independence of children, various supports for physical and psychological well-being are emphasized, the support by family has a direct influence to the depression of the elderly, shows the defense effect on the distress of the elderly, decrease the side effect of emotional aspect, which revealed the support by family is very useful to the satisfaction on the life of the elderly [3]. Since the support by family plays a role to control the influence on unexpected life change, it can be said to speed up the resilience recovery of human being, keep the quality of life.

This can be regarded as an important process which can establish multi-dimensional and informal support system which can control the loneliness and solitude of the elderly in their late stage in the situation of Korea in which the elderly suicide rate has been rapidly increased. Therefore, we should maintain and enhance the health of daily life which is top priority for the elderly in their late stage, activate family support and assistance for the elderly in many ways, expand the systematized system to support the family in the elderly period, support and supplement the care system for the elderly living alone by developing the system that can substitute family. In this point of view, this study intends to suggest the basic data required to the research of effective plans that can enhance the satisfaction of life of the elderly by understanding the quality level of life of the elderly, family support which is supported to the elderly, and the health of daily life recognized by the elderly. 


\section{Process}

This study is a descriptive survey research that enhances the health of daily life of the elderly in their late stage, compensates family support system for the elderly, and analyzes the influence and relationship for the enhancement of quality of life in the successful and happy old age. The convenient sampling method was conducted for the home care elderly over 65 years who have used Welfare center and senior university in urban area, Korea. The survey was conducted to the elderly who can communicate and understand the contents of questionnaire, and agreed to participate in the research. For data collection, face-to-face survey was conducted by researchers who understood the purpose of research and received the training.

As a result of this research, in the total elderly population, the proportion of female elderly was higher than that of male elderly. The age distribution of the elderly, the elderly aged 75 to 84 accounts for a majority which is the highest, the elderly whose spouse passed away account for $50 \%$, the elderly living alone took up the majority. The health of elderly who belong to the early stage showed high level while the elderly aged over 85 showed gradual decline. For the level of family support and quality of life, the elderly in their early stage showed higher level while the elderly in their late stage showed lower level.

The health factor showed higher explanation power in the super-aged elderly rather than quality of life in the elderly in their early stage. In the relationship of the health of the elderly and quality of life of the super aged group, the family support has a meditating effect over the all age groups, when the age group is higher, it showed less mediating effect. Unlike other research which regarded the elderly as a unified group, as a result of detailed classification by age group, this study proved that the elderly people health is different according to the quality of life in the elderly. And, as the age increases, the physical health is the main variable explaining the quality of life in the old age.

\section{Conclusion and Discussion}

It is necessary to build the customized care service delivery system for super aged elderly who lost the ability of daily life, the individualized support and interference in which the desire by age group is reflected such as health prevention program for the elderly in their early stage, and health improvement and vitality enhancement program for the elderly in their mid- stage. In addition, the psychological health appeared as an important factor over the all age group, it is found the emotional health of the old age has an important influence on the satisfaction of life of the elderly [4].

The daily physical activities of Korean elderly showed decline in the ability of independent life as their age increases, the proportion of care showed higher, it is necessary to conduct the national level program to improve the daily life fitness of the elderly by age group, class and region [5]. In addition, a detailed and diverse health and fitness supplement program should be expanded and applied to even the elderly who are disadvantaged in the region so that it can improve the ability for basic life health activity, maintain the ability of independent activity in daily life by implementing the exercise prescription support system by age group as a result of survey of the elderly health situation.

Second, in case of daily psychological life activity, as the age of Korean elderly increases, the positive life decreases, various channels such as psychological health activity program in old age, the positive image silver contents for vitality, education, consultation, public media and public advertisement should be discovered to expand and supply to the entire elderly population. Through this, the implications by OECD report that the suicide rate of Korean elderly people is the highest, the poverty rate of the elderly is the highest, the quality of life is the lowest should be analyzed and mended at the national level [6]. Actively supporting and preparing the psychological daily life of the elderly, who takes up the majority of total population, will be the foundation for successful old age society by improving the psychological healthy life in daily life in the national level.

Third, the daily life activities of the Korean elderly are greatly reduced as the age increases. For this purpose, it is necessary to prepare retirement preparation and reemployment preparation education which can supplement the social life activities of Korean elderly which decline rapidly after retirement [7]. We need to seek out the social atmosphere of active seniors so that they can actively participate in productive social life in the old age.

Fourth, as the younger the elderly in Korea, the subjective psychological well-being on family relations and family support is much lowered. This is because the younger the elderly in Korea, the greater the burden of family support due to the care of their children and the care of their grandchildren, which showed the degradation of quality of life. That is, the rate of living as kangaroo parents is high, as especially the ratio of the late marriage and non-marriage due to serious unemployment crisis increases, the elderly in their early stage who are still supporting the adult children in their late 20 s to late 30 s, the elderly in their mid- stage who are economically, temporally, physically, and emotionally exhausted due to grandchildren 's raising of grandchildren and the late marriage of children in their late $30 \mathrm{~s}$ $\sim$ in their late 40 s increase than the past, which result that the younger the elderly, the lower the quality of life.

Therefore, in terms of the integration of the generation, it is necessary to classify and implement the methods of supporting the childcare of the dual income couple, supporting the elderly who care for their grandchildren, and improving family relations education, counseling, and program support by age group, relation. Although the number of family members is gradually decreasing, family problems have become more diverse, and measures for restoring resilience and family crisis interventions for healthy family relationships should be sought more 
specifically and a practical response strategy for future family welfare policies is required.

Fifth, the subjective psychological well-being of the elderly in Korea is gradually lowered as the age of the elderly increases. For this, it is necessary to multi dimensionally seek ways to improve life satisfaction and social welfare of the elderly. According to the 2015 Quality of Life Report, the satisfaction level of life in the elderly population over the age of 50 was announced to the lowest level, showing that the subjective psychological well-being of Korean elderly people is the lowest in the world [8]. Especially, the result of the anxiety of the elderly in Korea is higher as they are older, suggests that the significance as an important research in which a low life well - being of older elderly is applied.

Therefore, the elderly welfare policy and the elderly welfare service should be developed, built to support the support system and resource in the local community so that elderly can participate actively and become independent by embodying and activating health promotion, social participation, counseling program, they can restore and maintain their potentiality and vitality by supplementing the shrunken relationship.

Currently, Korea is in the process of demographic structure reversal. In particular, the working age population aged 15 to 64 is beginning to decrease and life expectancy is increasing, which is a global trend, but the rate of aging of the Korean population shows 'its unprecedented top speed' accompanied with 'ultra low birth late. Therefore, we should continuously arrange the national and social structure and joint response strategies in order to prepare for the imminent reality of the super aged society according to the transition society of the demographic structure.

\section{References}

1. (2016) Elderly Statistics. National Statistical Office.

2. Mi Ran Lee (2012) Interaction effects of age group and demographic and social characteristics on self-integration of the elderly. Family and Environment Research 50(3): 95-109.

3. Mi Ran Lee (2014) The effect of health on the self-integration of old age, Integrated Conference Presentations data collection commemorating the $10^{\text {th }}$ anniversary of the Basic Law on Healthy Families enactment. p. 232.

4. Mi Ran Lee (2016) Change of Falls Efficacy and Cognition in Different Types of Healthy Leisure Program for Elders in Community. Proceedings of the $9^{\text {th }}$ International Workshop, The Convergent Research Society among Humanities, Sociology. Science and Technology, pp. 19-21.

5. Mi Ran Lee, Hee Eun Nam, Seon Hee Kim (2016) Effect of Exercise Prescription Service Customized for the Elderly in Community. International Journal of Bio-Science and Bio-Technology 8(3): 85-100.

6. Mi Ran Lee (2017) Study on Suicide Research Trends in Korean Elderly through Key Words. International Journal of IT-based Social Welfare Promotion and Management 4(1): 13-18.

7. Samsung life retirement research institute

8. (2016) Rapidly aging Korea-Preparing the old age is far from enough, The Segye Times.

\section{Your next submission with Juniper Publishers} will reach you the below assets

- Quality Editorial service

- Swift Peer Review

- Reprints availability

- E-prints Service

- Manuscript Podcast for convenient understanding

- Global attainment for your research

- Manuscript accessibility in different formats

( Pdf, E-pub, Full Text, Audio)

- Unceasing customer service

Track the below URL for one-step submission https://juniperpublishers.com/online-submission.php 